\title{
Um olhar sobre vinhetas e ornamentos tipográficos: O Catálogo de 1930 da Tipografia Hennies Irmãos \& Cia.
}

\author{
A look at vignettes and typographic ornaments: \\ the 1930 specimen book by Hennies Irmãos \& Cia. Letterpress Printing Shop
}

Jade Samara Piaia, Priscila Lena Farias

memória gráfica, cultura visual, tipografia, ornamentos tipográficos, vinhetas, São Paulo

Este artigo objetiva contribuir para estudos relacionados à memória gráfica paulistana e brasileira, em especial no que tange aos ornamentos tipográficos e vinhetas, a partir da análise de um catálogo de clichês e suprimentos gráficos publicado em 1930. Os métodos exploram, além da coleta e o tratamento dos dados, a organização do repertório dos elementos tipográficos não verbais para disponibilização em uma plataforma on-line. Os resultados compreendem a identificação de 628 elementos distribuídos em 10 conjuntos de ornamentos e 46 conjuntos de vinhetas que refletem um aspecto da cultura visual brasileira do início do século XX.

graphic memory, visual culture, typography, typographic ornaments, vignettes, São Paulo

This article aims to contribute to studies related to São Paulo city and Brazilian graphic memory, with particular regard to typographic ornaments and vignettes, from an analysis of a catalogue of clichés and graphic supplies published in 1930. The methods explore, besides data collection and treatment, the organization of the repertoire of non-verbal typographic elements to be made available on an online platform. The results comprise the identification of 628 elements distributed in 10 sets of ornaments and 46 sets of vignettes that reflect an aspect of Brazilian visual culture in the early twentieth century.

\section{Introdução}

Esse estudo se insere em um conjunto de investigações que almejam contribuir para uma melhor compreensão da memória gráfica nos primeiros cem anos de impressão tipográfica em São Paulo. Integra um estudo mais amplo que engloba o repertório da Tipografia Hennies Irmãos, no contexto das oficinas tipográficas paulistanas, com atuação do final do século XIX ao XX, investigando suas origens e influências, passando por sua trajetória centenária. A Tipografia Hennies Irmãos foi fundada pelos imigrantes alemães Heinrich Hennies e Theodor Hennies em 1891. A empresa foi ativa durante um século, produzindo artefatos impressos destinados aos mais variados setores da sociedade e às comunidades de imigrantes em São Paulo.

Um raro exemplar da memória gráfica paulistana é objeto deste estudo: o Catálogo (Hennies Irmãos \& Cia, 1930), publicação contendo ornamentos, vinhetas e materiais gráficos comercializados na cidade de São Paulo no início do século XX. Embora datado de 1930, os

Anais do $10^{\circ} \mathrm{CIDI}$ e $10^{\circ} \mathrm{CONGIC}$

Kelli C.A.S. Smythe, Rafael de Castro Andrade (orgs.)

Sociedade Brasileira de Design da Informação - SBDI

Curitiba | Brasil | 2021
Proceedings of the $10^{\text {th }} \mathrm{CIDI}$ and $10^{\text {th }}$ CONGIC

Kelli C.A.S. Smythe, Rafael de Castro Andrade (orgs.)

Sociedade Brasileira de Design da Informação - SBDI Curitiba | Brazil | 2021 
ornamentos e vinhetas contidos neste volume foram observados em uso desde a primeira década do século XX nas publicações impressas pelos Hennies.

Este artigo tem como objetivo contribuir para estudos relacionados à memória gráfica paulistana ao coletar e catalogar o repertório de elementos tipográficos não alfabéticos da Tipografia Hennies, mais precisamente ornamentos e vinhetas, a partir do Catalogo ${ }^{1}$ (Hennies Irmãos \& Cia, 1930). Há uma escassez de registros e ainda muitas lacunas em aberto no campo de estudos sobre os artefatos gráficos produzidos no primeiro século de impressão com tipos móveis, tanto no país quanto especificamente em São Paulo. Constatou-se que há pouca sistematização envolvendo elementos tipográficos não verbais, fato apontado por autores como Priscila Farias (2001) e Plínio Martins Filho (2003). Os ornamentos e as vinhetas tipográficas foram frequentemente utilizados pelos Hennies na configuração do conteúdo de mensagens, na ornamentação de livros e revistas e especialmente na diferenciação entre anúncios comerciais, promovendo eficiência na comunicação em impressos no início do século $\mathrm{XX}$, o que relaciona este estudo aos primórdios do design da informação. Esta investigação se insere no campo da teoria e história do design da informação dentro da perspectiva da memória gráfica ao resgatar um artefato significativo da cultura material paulistana, expor e analisar seu conteúdo.

Os procedimentos metodológicos propostos anteriormente por Clara Gastelois (2018) e pelo Protocolo Geral (Farias et. al, 2021a) para pesquisas relacionadas à plataforma Tipografia Paulistana, adotados pelo LabVisual - Laboratório de Pesquisa em Design Visual - da FAU USP, laboratório no qual se concentra a presente pesquisa, foram revistos e aprofundados. As principais terminologias e literaturas relacionadas foram revisadas. Os resultados foram disponibilizados na plataforma Tipografia Paulistana ${ }^{2}$ que constitui um acervo digital que reúne imagens dos tipos utilizados nas oficinas tipográficas instaladas na cidade de São Paulo entre 1827 e 1927. Ao examinar a plataforma Tipografia Paulistana, verificou-se que haviam exemplares de ornamentos da oficina tipográfica d'O Farol Paulistano, e ilustrações, vinhetas e ornamentos encontrados nos almanaques do impressor Jorge Seckler, resultados de pesquisas anteriores desenvolvidas no LabVisual (Gastelois, 2018; Martins, 2018). Estes resultados divergem da amplitude de temas e variações disponíveis no catálogo dos Hennies, tornando-se necessária sua investigação e disponibilização.

\section{Terminologia}

A terminologia adotada neste artigo está baseada em autores como Porta (1958), Farias (2001), Garone Gravier (2015), e Lotufo (2019). Cabe iniciar pelo termo vinheta, que pode ser entendido basicamente como uma "pequena ilustração colocada em anúncio ou trabalho gráfico" (ABC da ADG, 2012, p. 191). Frederico Porta define vinhetas como ornatos tipográficos baseados em formas geométricas ou figurativas, e 'vinhetas alegóricas' como aquelas que "representam uma ideia, mediante similitudes ou símbolos" (Porta, 1958, p. 412). Ornato pode ser entendido como um termo mais abrangente, que abarca ornamentos, vinhetas e outros

\footnotetext{
${ }^{1}$ Título da obra na versão original, sem acento.

2 Disponível em: <https://www.fau.usp.br/tipografiapaulistana/>. Acessado em maio de 2021.
} 
elementos tipográficos com função decorativa. Segundo Porta (1958, p. 297), ornato seria um elemento visual utilizado para embelezar composições tipográficas, diferindo da ilustração.

É comum, no linguajar do meio gráfico, se referir a vinhetas e ornamentos pelo termo clichê.Porta (1958, pp. 79-80), entretanto, define clichê como "placa de metal, com imagens ou dizeres em relevo, obtida por meio da estereotipia, galvanotipia ou fotogravura, e destinada à impressão em máquina tipográfica", podendo ser à traço ou meio tom (retícula), definição similar à fornecida por James Craig (1980).

Vinhetas foram um dos tópicos da pesquisa de Laura Lotufo (2019), que examinou folhas de rosto de livros impressos em São Paulo entre os séculos XIX e XX. Lotufo observou que as vinhetas eram frequentemente utilizadas nas folhas de rosto como elementos de separação entre as informações da parte superior e os dados de imprenta, posicionados na parte inferior.

Segundo Priscila Farias (2001), fontes tipográficas contendo elementos tipográficos não alfabéticos podem ser divididas em: abstratas (compostas por pequenos elementos utilizados em padronagens ou composições maiores), ilustrativas (com desenhos figurativos), e informativas (compostas por pictogramas ou símbolos com significado preciso). Marina Garone Gravier (2015), por sua vez, utiliza o termo ornamento para elementos tipográficos não alfabéticos, e os divide entre elementos abstratos, figurativos ou arabescos, divisão esta que foi adaptada e ampliada por Gastelois (2018). Segundo Garone Gravier (2015, pp. 90-94), ornamentos são peças de metal fundido, assim como os caracteres tipográficos. Eles podem ser usados para decorar, delimitar áreas de informação, separar áreas de texto e indicar seções.

O termo clichê é aqui entendido como a peça física utilizada para a impressão de imagens ou composições. O termo vinheta é usado para elementos ilustrativos, figurativos e informativos, e o termo ornamento para imagens abstratas ou figurativas em menor tamanho, frequentemente adotadas em molduras.

\section{Origens}

Segundo Garone Gravier (2015) a ornamentação tem origem nos adornos caligráficos dos escribas aplicados em letras capitulares e molduras de caixas de texto, prática que passou por um processo de simplificação com o advento da mecanização da impressão tipográfica, se manifestando, a partir de então, primeiro nos arabescos que adornavam encadernações de livros, com posterior migração dos ornamentos para as páginas internas dos livros (ver também Jury, 2015).

Padrões e elementos aplicados em diferentes estilos de ornamentação nas artes e na arquitetura utilizados em distintas regiões do planeta foram compilados na obra de Owen Jones (1910), que inclui exemplos de iluminuras medievais, amostras italianas de capitulares, frontões para uso tipográfico e capitulares decoradas que remetem ao estilo Vitoriano, referência nos estudos sobre estilos de ornamentos. Exemplos de variedades de motivos decorativos e da construção gráfica de padrões podem ser vistos na obra de Franz Sales Meyer (1894), que inclui uma seção dedicada à decoração de objetos, com amostras de ornamentação voltadas para encadernações de livros e uma subdivisão dedicada à ornamentação de letras. O hábito 
de ornamentar, como indicam os autores, se manifestava há tempos em objetos do cotidiano quando foi incorporado à impressão tipográfica.

De acordo com David Jury (2015) os primeiros registros de impressão decorativa teriam sido obtidos a partir de tiras de madeira gravadas à mão utilizadas para estampar bordas decorativas, que datam de meados de 1470, vinte anos após o advento da impressão com tipos móveis por Gutenberg. Estampas individuais de flores teriam sido, segundo o autor, desenvolvidas em carimbos de latão, e usadas para decorar encadernações com capas de couro. O uso de ornamentos na Europa, segundo Jury (2015), teria sofrido influência dos habilidosos artesãos árabes instalados na Itália no século XVI e dos estilos artísticos barroco, rococó e Luís XV, com muitos novos desenhos de ornamentos refinados e extravagantes permeando o universo tipográfico no século XVIII.

Características do final do século XIX, as ricas composições com ornamentos tipográficos estavam em alta nas décadas de 1860 e 1870 em 'impressos artísticos', um estilo decorativo de tipografia, segundo Clouse \& Voulangas (2009). As famílias de ornamentos que Clouse \& Voulangas (2009, pp. 20,45) denominam 'bordas de combinação', continham cantos e molduras decorativas, fitas decoradas, elementos florais e pequenas paisagens. Seu uso combinava bordas e ornamentos com tipos engenhosamente projetados para encaixar na horizontal, vertical ou diagonal.

Com relação ao uso de vinhetas em textos e anúncios comerciais, Plinio Martins Filho (2003) aponta que o fenômeno do uso de imagens junto a textos, visto inicialmente na França por volta de 1820, tornou a relação texto-imagem mais atrativa para o leitor. Esta combinação de imagem e texto, segundo Martins Filho (2003), teria se tornado imprescindível em impressos do século $X X$.

Segundo Jury (2015), eram comuns ornamentos derivados de formas naturais florais e arabescos clássicos envolvendo flores, folhas e galhos em simetria. Ornamentos geométricos e simplificados teriam, de acordo com o autor, se tornado mais populares após a Primeira Guerra Mundial, quando a ornamentação complexa e rebuscada do final do século XIX caiu em desuso, devido ao pensamento modernista e ao aumento da produção de bens industrializados. As vinhetas teriam se popularizado rapidamente nos séculos XIX e XX, através da reprodução em massa pela técnica da estereotipia, sendo frequentemente utilizadas como índices visuais em anúncios comerciais (Jury, 2015, pp. 188-189). Vinhetas e ornamentos, segundo o autor, teriam desaparecido no final do século $X X$, junto com a impressão com tipos móveis na função comercial, mas sua ideia teria permanecido nos 'clip arts' digitais do início do século XXI (Jury, 2015, pp. 191).

\section{Métodos}

Um primeiro olhar sobre o Catalogo (Hennies Irmãos \& Cia, 1930) seguiu os procedimentos adotados por Aragão, Farias e Lima (2014) em um estudo sobre catálogos de tipos de 
fundidoras brasileiras dos séculos XIX e XX. Em uma análise inicial, as características gráficas do impresso, a configuração e a organização do catálogo foram observadas e relatadas.

Os métodos de coleta, tratamento e organização dos dados visuais seguiram os protocolos adotados no LabVisual (Farias et. al, 2021a; 2021b). A coleta incluiu a digitalização das páginas através de scanner plano em $300 \mathrm{dpi}$ e o tratamento das imagens foi realizado no software Adobe Photoshop visando ajustes de contraste, nitidez e alinhamento, preservando o tamanho original (figura 1). Posteriormente, os ornamentos e vinhetas foram medidos, recortados individualmente e salvos para web.

Figura 1: Exemplo de página do Catalogo (Hennies Irmãos \& Cia, 1930, p. 3), coletada e tratada.


NOTA: Pede-se indicar nas encommendas o numero da pagina e do eliché

A organização dos dados partiu da nomenclatura dos arquivos gerados após o tratamento, o que levou em conta os procedimentos adotados por Gastelois (2018) ao investigar elementos tipográficos não verbais (ilustrações, vinhetas e ornamentos) presentes nos almanaques comerciais de Jorge Seckler. Alguns ajustes na nomenclatura codificada originalmente proposta por Gastelois (2018) foram realizados. Junto à sigla da oficina tipográfica foi incluída uma sigla referente à publicação. Ano, página e linha foram mantidos, seguidos pela posição do elemento na linha e pelo código do elemento no catálogo. Por último, entre colchetes, foi inserida uma palavra para descrever o elemento (tabela 1). 
Tabela 1: Exemplo de vinheta tratada e recortada com detalhamento da composição da nomenclatura codificada utilizada para nomear arquivos de imagem.



As imagens tratadas foram nomeadas e organizadas em pastas por temas, correspondentes às nomenclaturas dos conjuntos compostos com estes elementos, e separadas em pastas por corpo (tamanhos), correspondentes às gavetas.

Os dados coletados foram organizados em uma planilha que partiu da ordem sequencial das amostras no catálogo, título -que muitas vezes remete ao preço de venda do clichê-, número da página e corpo. Breves descritivos (tesoura e lâmina barbear; luvas; porco) e temas (objeto; vestuário; animal) foram criados para organizar os elementos. A planilha incluiu ainda dados para cadastro na plataforma Tipografia Paulistana, como categoria (não latina), tipo (ornamento; vinheta), nome do arquivo gerado, nome da família tipográfica (ou, neste caso, conjunto de elementos tipográficos) a ser criada na plataforma, um check-list do andamento da coleta e tratamento dos dados, e os links para os arquivos na plataforma Google Drive e para o conjunto de caracteres disponibilizado na plataforma Tipografia Paulistana (figura 2).

Figura 2: Detalhe da planilha de organização dos dados.

\begin{tabular}{|c|c|c|c|c|c|c|c|c|c|c|}
\hline \multirow[b]{2}{*}{$\mathbf{N}^{\circ}$} & \multicolumn{6}{|l|}{ Catálogo, 1930} & \multicolumn{4}{|c|}{ Tipografia Paulistana } \\
\hline & Nomenclatura Hennies & & Corpo & Descritivo & Tema & & Categoria & Tipo & Nome do arquivo & Nome da fonte \\
\hline 1 & Preço de cada cliché $\mathbf{2} \$ 500$ & 3 & 40 & tesoura e lâmina bal & objeto & - & não latina & vinheta - & THICAT_1930_3_1_1_496__tesoura] & Vinhetas $N .^{\circ} 47$ \{objetos\} \\
\hline 2 & Preço de cada cliché $2 \$ 500$ & 3 & 40 & binóculo & objeto & - & não latina & vinheta $=$ & THICAT_1930_3_1_2_554_[binoculo] & Vinhetas $N .^{\circ} 47$ \{objetos\} \\
\hline 3 & Preço de cada cliché $2 \$ 500$ & 3 & 40 & luvas & vestuário & - & não latina & vinheta & THICAT_1930_03_1_3_552_lluva] & Vinhetas $\mathrm{N} .{ }^{\circ} 57$ \{vestuário\} \\
\hline 4 & Preço de cada cliché $2 \$ 500$ & 3 & 40 & carrinho de bebê & objeto & - & não latina & vinheta ${ }^{2}$ & THICAT_1930_03_1_4_551_ccarrinhol & | Vinhetas N. ${ }^{\circ} 47$ \{objetos\} \\
\hline 5 & Preço de cada cliché $2 \$ 500$ & 3 & 40 & brasão com martelo & emblema & - & não latina & vinheta ${ }^{2}$ & THICAT_1930_03_1_5_560_brasão] & Vinhetas $\mathrm{N} .^{\circ} 36$ \{brasões\} \\
\hline 6 & Preço de cada cliché $2 \$ 500$ & 3 & 56 & porco & animal & - & não latina & vinheta $=$ & THICAT_1930_03_2_1_591_[porco] & Vinhetas $N .^{\circ} 18$ \{animais\} \\
\hline 7 & Preço de cada cliché $2 \$ 500$ & 3 & 56 & alvo e arn & esporte & - & não latina & vinheta ${ }^{2}$ & THICAT_1930_03_2_2_571_ttiroaoalv & Vinhetas $\mathrm{N} .{ }^{\circ} 37$ \{esportes\} \\
\hline 8 & Preço de cada cliché $2 \$ 500$ & 3 & 56 & chapéu & chapéu & - & não latina & vinheta ${ }^{2}$ & THICAT_1930_03_2_3_559_[chapeu] & Vinhetas $N .^{\circ} 25$ \{chapéus\} \\
\hline 9 & Preço de cada cliché $2 \$ 500$ & 3 & 56 & relógio & relógio &  & não latina & vinheta ${ }^{2}$ & THICAT_1930_03_2_4_2580_[relogio] & Vinhetas $N .^{\circ} 52$ \{relógios\} \\
\hline 10 & Preço de cada cliché $2 \$ 500$ & 3 & 56 & cesta & objeto & - & não latina & vinheta ${ }^{-}$ & THICAT_1930_03_2_5_580_[cesta] & Vinhetas $N .^{\circ} 47$ \{objetos\} \\
\hline 11 & Preço de cada cliché $2 \$ 500$ & 3 & 72 & brasão c & emblema & - & não latina & vinheta & THICAT_1930_03_3_1_530_brasao] & Vinhetas $N .^{\circ} 36$ \{brasōes\} \\
\hline 12 & Preço de cada cliché $2 \$ 500$ & 3 & 40 & galinha & aves & - & não latina & vinheta ${ }^{2}$ & THICAT_1930_03_3_2_2487_Igalinha & Vinhetas $\mathrm{N} .^{\circ} 20$ \{aves\} \\
\hline 13 & Preço de cada cliché $2 \$ 500$ & 3 & 28 & Haver & palavra & 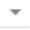 & escritural & vinheta ${ }^{2}$ & THICAT_1930_03_3_3_540_[haver] & Vinhetas $\mathrm{N} .{ }^{\circ} 48$ \{palavras\} \\
\hline 14 & Preço de cada cliché $2 \$ 500$ & 3 & 56 & termômetro & objeto & - & não latina & vinheta & THICAT_1930_03_3_4_599_ttermome & Vinhetas N. ${ }^{\circ} 47$ \{objetos\} \\
\hline 15 & Preço de cada cliché $2 \$ 500$ & 3 & 72 & cofre & móvel & 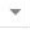 & não latina & vinheta $=$ & THICAT_1930_03_3_5_608_[cofre] & Vinhetas $\mathrm{N} .{ }^{\circ} 45$ \{móveis\} \\
\hline 16 & Preço de cada cliché $4 \$ 000$ & 3 & 50 & coelho & animal & - & não latina & vinheta ${ }^{-}$ & THICAT_1930_03_4_1_2480_[coelho] & Vinhetas $N .^{\circ} 18$ \{animais\} \\
\hline 17 & Preço de cada cliché $4 \$ 000$ & 3 & 50 & violino, instrumer & instrumen & & não latina & vinheta ${ }^{*}$ & THICAT_1930_03_4_2_522_linstrume & Vinhetas $\mathrm{N} .{ }^{\circ} 41$ finstrument \\
\hline 18 & Preço de cada cliché $4 \$ 000$ & 3 & 50 & galinha & aves & - & não latina & vinheta $=$ & THICAT_1930_03_4_3_2486_[galo] & Vinhetas $\mathrm{N} .^{\circ} 20$ \{aves\} \\
\hline 19 & Preço de cada cliché $4 \$ 000$ & 3 & 50 & sapato & calçado & 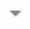 & não latina & vinheta ${ }^{-}$ & THICAT_1930_03_4_4_2588_[sapato] & Vinhetas $N .^{\circ} 23$ \{calçados\} \\
\hline
\end{tabular}

Posteriormente à inserção dos caracteres na plataforma foi elaborada uma planilha de resultados com o nome atribuído ao conjunto de elementos na plataforma, seguido das respectivas categorias e corpos. Essa planilha possibilitou calcular o total de elementos presentes em cada conjunto e o quantitativo por corpo. 


\section{Resultados}

O Catalogo (Hennies Irmãos \& Cia, 1930) apresenta as dimensões 152 x 222 mm, com capa impressa em papel sulfite e miolo em papel couchê, predominantemente em uma cor (preto) com algumas páginas em duas cores (preto e rosa claro) e uma página em quatro cores (cromia em preto, ciano, amarelo e rosa -algo próximo da cor magenta, mais claro.

A capa apresenta um breve descritivo e o nome da empresa no topo como "Typographia, Encadernação e Pautação / Hennies Irmãos \& Cia.", ao centro o título "Catalogo" e logo abaixo o ano "1930", com um fio sublinhando o nome da empresa e o título da publicação (figura 3). No rodapé consta a cidade, seguida do endereço. As principais informações foram compostas na fonte Block da fundidora alemã $\mathrm{H}$. Berthold, com exceção do endereço em fonte grotesca, a composição é centralizada com a hierarquia definida pelos corpos e pelo uso dos fios para sublinhar. Há uma moldura geométrica lisa formada por três fios com espessuras diferentes, de fora para dentro, do mais grosso para o mais fino, e um ornamento geométrico simples, quadrado preenchido com contorno, no centro.

Figura 3: Capa e folha de rosto do Catalogo (Hennies Irmãos \& Cia., 1930).


A folha de rosto repete estas informações com outras fontes tipográficas em uma composição mais leve com uso de letras inclinadas e grotescas, ocupando a primeira metade da folha, emoldurada por um fio simples (figura 3). Na parte inferior, traz a seguinte observação: 
Este Catalogo annula todos os anteriores. Fabrica de cartões em alto relêvo e aerographia. Importação de papeis, tintas. etc. Permanente deposito de todos os artigos e utensilios para typo e lithographias. Tintas, vernizes e seccativos para impressão da firma Dr. Loevinsohn \& Co. Berlim Friedrichsfelde (Allemanha). Machinas de costurar (com fio de arame), machinas de cortar papel, machinas de perfurar, prensa para encadernação, pinças e componedores para typographos. (Hennies Irmãos \& Cia, 1930, pp.1)

O texto revela a existência de catálogos anteriores e, tanto nele quanto ao final do catálogo, há menções a suprimentos gráficos -máquinas, utensílios, tintas e vernizes- de procedência alemã.

Ao analisar a disposição dos clichês de ornamentos e vinhetas, observou-se que estes estão organizados por preços, que parecem variar mais conforme o tamanho físico da peça do que em relação ao conteúdo (figura 4). Os ornamentos utilizados para composição de molduras são denominados no catálogo como 'vinhetas para guarnição'. Estas peças são mostradas separadas da composição da moldura e há também exemplos com duas cores de impressão (figura 4). As imagens de suprimentos gráficos são acompanhadas pela descrição dos respectivos equipamentos.

Figura 4: Páginas contendo vinhetas (clichês), molduras (vinhetas para guarnição) e suprimentos gráficos (máquinas e utensílios) do Catalogo (Hennies Irmãos \& Cia., 1930, pp. 17, 54, 62).

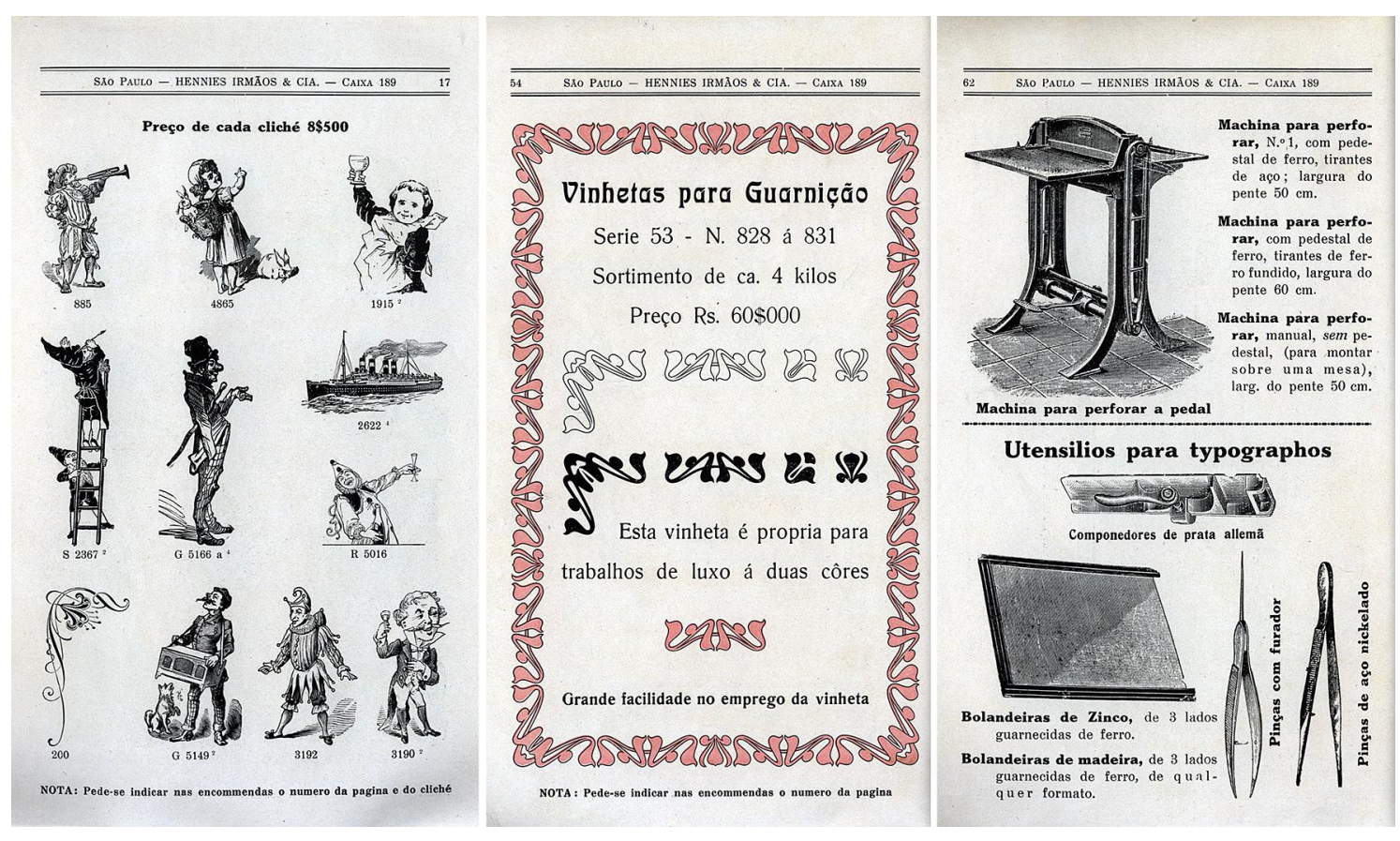

Os resultados compilados a partir do catálogo compreendem conjuntos temáticos de ornamentos e vinhetas. Os ornamentos foram organizados segundo 7 temas: círculos, entrelinhas, fios, florais, geométricos, molduras e orgânicos. Os conjuntos de vinhetas foram organizados segundo 42 temas: alimentos, animais, arabescos florais, aquáticos, aves, bovinos, cães e gatos, calçados, cavalos, chapéus, construção arquitetônica, cristianismo, decoração floral, decorativas série 78, eletrodomésticos, emblemas, esportes, ferramentas, figura humana, flores, floral cor, insetos, instrumentos musicais, mãos, máquinas, máquinas 
tipográficas, móveis, mulheres, objetos, palavras, personagens, plantas, produtos, profissões, relógios, rural, tiras temáticas, transporte aéreo-ferroviário-marítimo, transporte rodoviário, utensílios tipográficos, vestuários, 'vinhetas finaes'. Foram criados temas mantendo agrupamentos já existentes no catálogo e preservando suas nomenclaturas em raras ocorrências, como, por exemplo, 'decorativas série 78' e 'vinhetas finaes'. O tema 'palavras' contém vinhetas de grafia escritural rebuscada, como 'Factura', 'Nota' e 'Haver'. Os dois únicos elementos que diferem de ornamentos e vinhetas referem-se a caracteres numéricos de categoria serifada e compreendem 'números para folhinhas' (calendários).

A organização por temas foi essencial no agrupamento dos elementos tipográficos em conjuntos, para a posterior inserção destes na plataforma Tipografia Paulistana. As famílias tipográficas contendo elementos não verbais foram categorizadas como famílias 'não latinas' na plataforma, categoria que inclui caracteres não pertencentes ao alfabeto latino, e que pode englobar pictogramas, vinhetas e ornamentos.

Figura 5: Vinhetas $N .^{\circ} 33$ \{vinhetas finaes\} (detalhe) de página da plataforma Tipografia Paulistana.

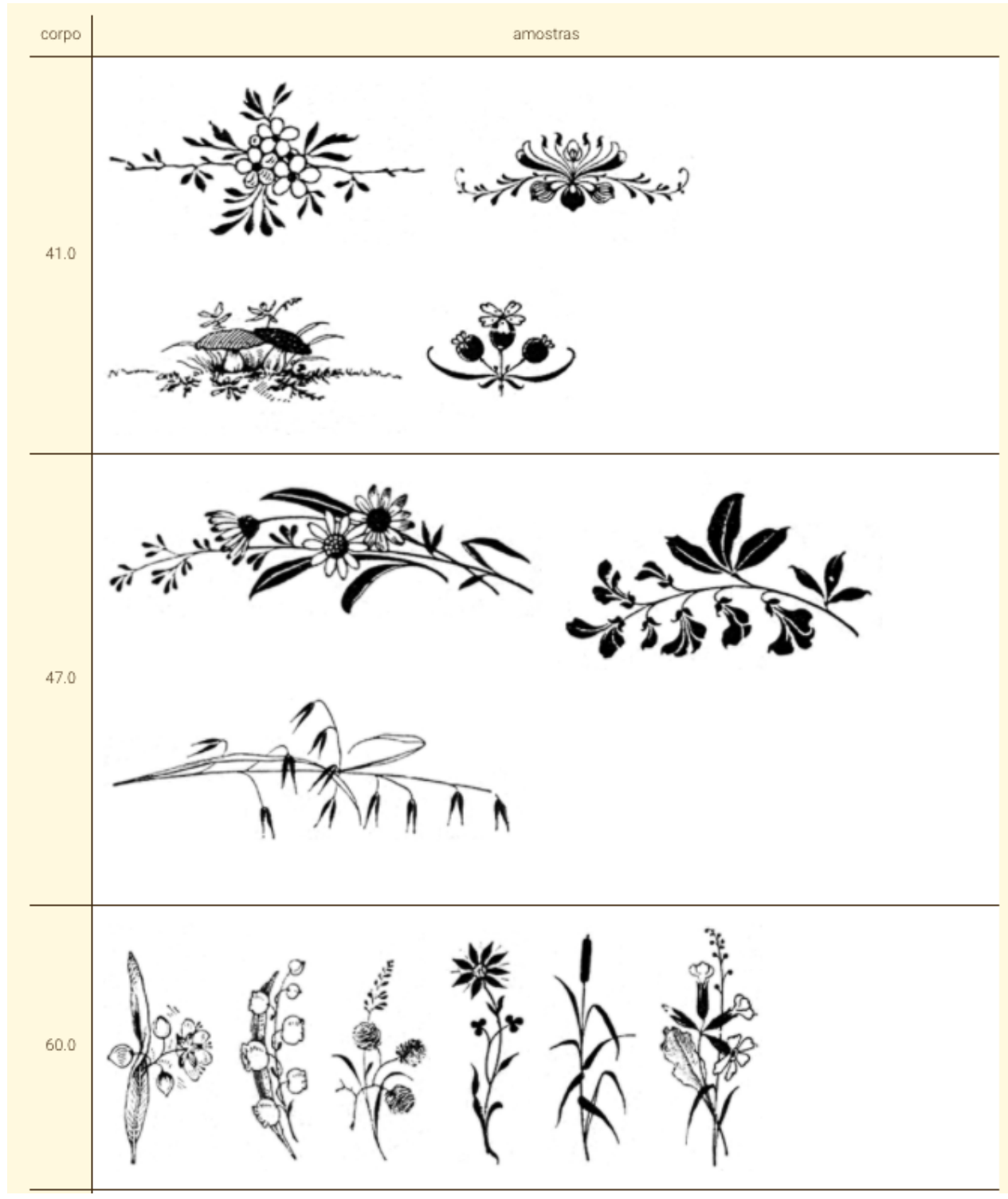


A organização dos elementos resultou em 10 conjuntos de ornamentos e 46 conjuntos de vinhetas. Os elementos não verbais foram agrupados em conjuntos por temas e em 'gavetas', com o mesmo tema e tamanho, e organizados na plataforma em 'famílias tipográficas', que compreendem o conjunto de 'gavetas' que aparecem juntas em uma página, como na figura 5. Foram criadas 54 novas famílias tipográficas com conjuntos de elementos na plataforma (de 57 fontes no total, que considerou uma fonte existente, complementada, e duas que continham vinhetas idênticas coletadas em outro catálogo dos Hennies), totalizando 628 caracteres inseridos. Os corpos vão de 2 pt a 555 pt, os corpos com mais elementos são: 58 pt, 56 pt, 48 pt, 64 pt e 80 pt. Houve a complementação do conjunto de elementos tipográficos de uma família serifada contendo caracteres numéricos (Serifada $n^{\circ} 40$ números). Estes resultados podem ser conferidos na plataforma Tipografia Paulistana no repertório da Tipografia Hennies <https://www.fau.usp.br/tipografiapaulistana/empresa/93>.

Dentre estes resultados, há um conjunto de ornamentos e duas vinhetas para impressão em duas cores (preenchimento e contorno), uma vinheta para impressão em três cores e outra para impressão em quatro cores. Na vinheta para impressão em três cores há um encaixe em áreas vazadas, como acontece na relação entre preenchimento e contorno, e naquela para impressão em quatro cores há sobreposição, por meio de hachuras e pequenos pontilhados, conferindo tonalidades diferentes à imagem (figura 6). As cores eram descritas como 'fundos' no catálogo, inclusos no preço da vinheta. Na plataforma Tipografia Paulistana, estas vinhetas foram agrupadas na família Vinhetas $\mathrm{N} .{ }^{\circ} 34$ \{florais cor $\}^{3}$, e representadas em duas versões: uma com as cores e uma somente com o elemento a ser impresso em preto.

${ }^{3}$ Disponível em: <https://www.fau.usp.br/tipografiapaulistana/familia/289>. Acessado em maio de 2021. 
Figura 6: Exemplos de vinhetas com impressão a cores, com detalhe da sobreposição de cores.



Os conjuntos com maior quantidade de elementos são os de objetos, animais, fios, 'vinhetas finaes' (florais), personagens, mãos, cristianismo e brasões. As vinhetas com temas florais, que somam 100 ilustrações, foram divididas em sete conjuntos. Algumas vinhetas de decoração floral compreendem peças únicas com espaço interno para inserção de palavras curtas na composição. As vinhetas contendo uma mão que aponta em uma direção —símbolo denominado de manicula por Sherman (2005) e indicador por Bringhurst (2018, p. 354) — estão presentes em diversas páginas do catálogo. Há sete conjuntos de ornamentos desenhados para serem utilizados na composição de molduras. Os números para folhinha do 1 ao 31 são descritos, no catálogo dos Hennies, como "estereotipias", assim como algumas mãos e uma imagem de mulher (figura 7). 
Figura 7: Imagem de mulher disponível como estereotipia e clichê (Hennies Irmãos \& Cia, 1930, pp. 13, 31).



$565^{2}$ estereot.

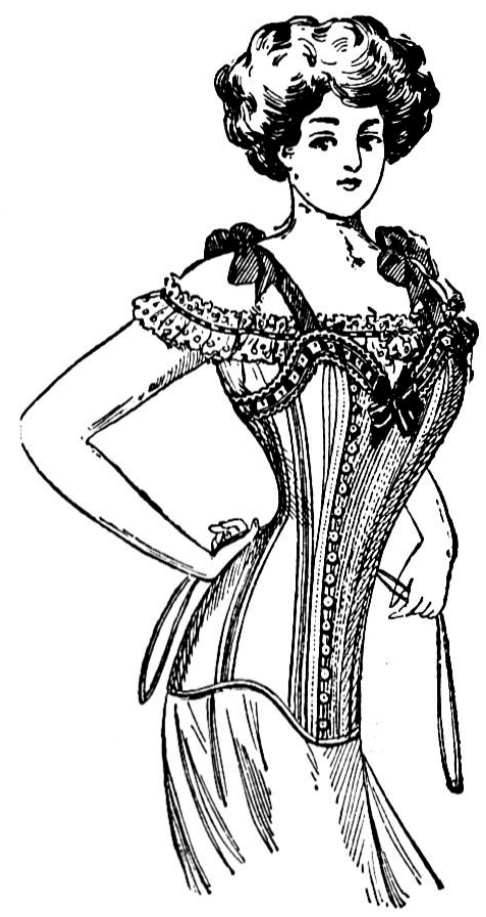

$56512 \$ 000$

\section{Discussão}

Com representações visuais características do século $X X$, o repertório de elementos tipográficos não verbais encontrado no Catalogo (Hennies Irmãos \& Cia, 1930) diverge daquele encontrado em artefatos gráficos do século XIX anteriormente catalogados na plataforma Tipografia Paulistana, como os d'O Farol Paulistano e os utilizados nos almanaques do impressor Jorge Seckler. Os ornamentos do repertório de Seckler, em sua maioria em corpos pequenos, apresentam características geométricas e abstratas, além de ornamentos para composição de molduras clássicas, geométricas e rebuscadas, características do século XIX. Há alguma semelhança entre as vinhetas de indicadores e algumas máquinas, mas eles diferem na maioria dos outros temas, nos brasões e medalhas.

Observou-se no repertório dos Hennies, a partir do catálogo examinado, a inexistência de ornamentos em estilo clássico ou excessivamente rebuscados. Ao mesmo tempo, verificou-se a predominância de elementos decorativos com características do estilo Art Nouveau. Há conjuntos de ornamentos florais utilizados para compor estruturas complexas, tais como caules com folhagens e terminações florais empregados para compor molduras e ilustrações em impressos refinados. Isso indica que os Hennies buscavam alinhar-se à linguagem visual da virada do século $X X$ e às tendências modernistas daquele período.

Parte das vinhetas pictóricas dos Hennies apresentam desenhos com formas simples e bem definidas, e outra parte contém ilustrações mais realistas, com preenchimentos e sombreados 
ricos em hachuras -traços finos que simulam diferentes planos e texturas-, semelhante às usadas em gravuras (figura 8).

Figura 8: Vinhetas lineares e hachuradas no Catalogo (Hennies Irmãos \& Cia, 1930, pp. 31, 26), e utilizada em anúncio publicado na Revista Album Imperial, em 1907 (ano 2, n² 23, 3a capa). Acervo da seção de Obras Raras da Biblioteca Nacional.


Algumas vinhetas foram encontradas também em outras publicações impressas pelos Hennies datadas dos primeiros anos do século XX. Um anúncio de 1907 que traz a vinheta de um par de luvas em meio ao nome do estabelecimento comercial Luvaria Martins (figura 8) é um exemplo disso. $\mathrm{O}$ alto número de vinhetas no catálogo com os mais diversos temas está relacionado à necessidade de ilustrar e diferenciar anúncios comerciais em jornais e revistas para atrair a atenção do leitor.

Os elementos não tipográficos do catálogo incluem elementos ilustrativos, informativos, abstratos e palavras. Os elementos ilustrativos, que constituem a maioria das vinhetas do catálogo, tem temas variados. Os elementos informativos incluem símbolos de profissões, religiosos, mitológicos e brasões -como o brasão da República, brasões alemães e portugueses. Os elementos abstratos, compreendem círculos, entrelinhas e fios de latão, além de ornamentos para composição de molduras. As palavras apresentam sempre grafia escritural.

Os Hennies se empenharam na publicação de livros e periódicos nas primeiras décadas de atuação, muitos deles voltados a comunidades de imigrantes que se estabeleceram em São Paulo e arredores. Apesar de também terem trabalhado com impressão litográfica, sempre se definiram como tipografia, principal atividade da empresa. O exame deste catálogo revela uma ampla gama de recursos gráficos disponíveis aos tipógrafos nas primeiras décadas do século XX. 


\section{Conclusão}

Ornamentos e vinhetas eram muitas vezes a única informação não textual presente na composição de impressos tipográficos, seja como informação pictórica, de função ilustrativa junto à informação textual, ou organizados e combinados esquematicamente em molduras, divisores ou cantos na ornamentação de páginas. As vinhetas pictóricas tiveram papel importante junto às escolhas tipográficas, responsáveis pela diferenciação de anúncios comerciais de empresas concorrentes.

O ornamento constitui substrato material básico da tipografia, segue as configurações de tamanho dos caracteres em pontos, o que permite o uso junto aos demais caracteres na composição tipográfica. A confecção de impressos ornamentados é uma atividade que envolve um alto nível de complexidade na composição manual com tipos móveis com grande potencial expressivo. Estes elementos tipográficos não verbais funcionam efetivamente como uma linguagem universal que todos podem compreender, tornam o material impresso mais fácil de ler e esteticamente mais agradável.

Os resultados revelaram um rico banco de imagens pronto para ser utilizado em uma ampla gama de anúncios comerciais. A diversidade de temas cobre desde os setores agrícolas, esportes e lazer até itens refinados de vestuário, para ilustrar os mais diversos temas, delicados como arranjos florais e inusitados como alguns personagens, e para atender funções específicas como as maniculas e as palavras manuscritas para uso em faturas e notas.

Neste estudo não foi possível identificar com precisão a origem do repertório de vinhetas e ornamentos comercializado pelos Hennies, mas acredita-se que ao menos uma parte dele tenha origem alemã. A disponibilização destes resultados pode fomentar outros estudos similares no resgate da memória gráfica paulistana e brasileira, e na investigação de suas origens.

Este resgate histórico de ornamentos e vinhetas que circulavam em São Paulo contribui para compreensão da variedade de elementos disponíveis aos tipógrafos, no início do século $X X$, para compor mensagens visuais atrativas ao leitor, e atender às necessidades dos editores e anunciantes em jornais, revistas e almanaques.

\section{Agradecimento}

Esta pesquisa foi apoiada por bolsas de Pós-Doutorado da Fundação de Amparo à Pesquisa do Estado de São Paulo (FAPESP, n 2019/07566-6), e de Produtividade em Pesquisa (CNPQ, $\left.n^{\circ} 304361 / 2019-4\right)$.

\section{Referências}

Aragão, I., Farias, P. L., Lima, E. L. C. (2014). Um estudo sobre catálogos de tipos de fundidoras brasileiras dos séculos 19 e 20. In: Coutinho, S. G.; et. al (orgs.). Proceedings of the 6th Information Design International Conference, 5th InfoDesign, 6th CONGIC [= Blucher Design Proceedings, num.2, vol.1]. São Paulo: Blucher. 
Associação dos Designers Gráficos - ADG Brasil. (2012). ABC da ADG: Glossário de termos e verbetes utilizados em Design Gráfico. São Paulo: Blucher.

Bringhurst, R. (2018). Elementos do Estilo Tipográfico. São Paulo: Ubu, v. 4.0.

Clouse, D. \& Voulangas, A. (2009). The Handy Book of Artistic Printing: A Collection of Letterpress Examples with Specimens of Type, Ornament, Corner Fills, Borders, Twisters, Wrinklers, and other Freaks of Fancy. New York: Princeton Architectural Press.

Craig, J. (1980). Produção gráfica: para planejador gráfico, editor, diretor de arte, produtor, estudante. 2. ed. São Paulo: Mosaico: Ed. da Universidade de São Paulo.

Farias, P. L. (2001). Fontes que não servem para escrever: algumas considerações sobre o status tipográfico dos dingbat. Revista da ADG, n. 23 pp. 49-51. In: Farias, P. L. (2016). Estudos sobre tipografia: letras, memória gráfica e paisagens tipográficas. Tese de LivreDocência, pp. 33-35. Universidade de São Paulo. Faculdade de Arquitetura e Urbanismo.

Farias, P. L., et. al. (2021a) Protocolo Geral - Tipografia Paulistana. LabVisual, FAU USP. (manuscrito não publicado)

Farias, P. L., et. al. (2021b) Protocolo de Tratamento de Imagem - Tipografia Paulistana. LabVisual, FAU USP. (manuscrito não publicado)

Martins Filho, P. (2003). Catálogo de Clichês D. Salles Monteiro. São Paulo: Ateliê Editorial.

Gastelois, C. O. (2018). Memória Gráfica Paulistana: ilustrações, vinhetas e ornamentos tipográficos nos almanaques comerciais de Jorge Seckler. Relatório Final de Iniciação Científica PIBIC 2017/2018. Orientadora: Priscila Lena Farias. São Paulo, FAU USP. (não publicado)

Garone Gravier, M. (2015). Historia de la imprenta y la tipografia colonial em Puebla de los Angeles. México, D.F.: Universidad Nacional Autónoma de México, Instituto de investigaciones Bibliograficas, Biblioteca Nacional.

Hennies Irmãos \& Cia. (1930). Catalogo. São Paulo: Tipografia, Encadernação, Pautação, Hennies Irmãos \& Cia. Acervo: Família Hennies.

Jury, D. (2015). The Little Book of Typographic Ornament. London: Laurence King Publishing.

Lotufo, L. B. (2019). Rostos tipográficos: a tipografia das folhas de rosto impressas na cidade de São Paulo (1836-1918). Dissertação (Mestrado em Design), Faculdade de Arquitetura e Urbanismo, Universidade de São Paulo, São Paulo.

Martins, B. T. (2018). Letras a vapor: o repertório tipográfico dos impressores paulistanos do século XIX. Relatório Final de Iniciação Científica Bolsa PUB 2017/2018. Orientadora: Dra. Priscila Lena Farias. São Paulo, FAU USP. (não publicado)

Meyer, F. S. (1894). Handbook of ornament. A grammar of art industrial and architectural designing in all its branches for practical as well as theoretical use. 8 ed. Leipzig: Seemann.

Jones, O. (1910). The grammar of ornament. v. 1. London: Bernard Quaritch.

Porta, F. (1958). Dicionário de Artes Gráficas. Rio de Janeiro: Ed. Globo.

Sherman, W. H. (2005). Toward a History of the Manicule. <http://www.livesandletters.ac.uk/> 


\section{Sobre as autoras}

Jade Samara Piaia, Pesquisadora de Pós-doutorado, FAUUSP, Brasil.<jadepiaia@usp.br>

Priscila Lena Farias, Professora Associada, FAUUSP, Brasil. <prifarias@usp.br> 